\title{
MOBILE PAYMENT AND MOBILE MONEY TRANSFER ON PERFORMANCE OF MICRO, SMALL AND MEDIUM ENTERPRISES IN KENYA.
}

\author{
Mbithi George Mutiso ${ }^{\mathrm{a}}$, Dr. James Mwikya Reuben ${ }^{\mathrm{b}}$ \\ aDepartment of Business Administration, Management University of Africa, \\ P.O Box 29677-00100, Nairobi Kenya \\ bepartment of Computing and Information Technology, Kirinyaga University, \\ P.O.Box: 143-10300, Kerugoya Kenya \\ ambithig@gmail.com, bjmwikya@kyu.ac.ke
}

\begin{abstract}
$\underline{\text { Abstract }}$
According to a survey carried out by the Kajiado East Constituency development fund and contained in a document titled Kajiado East Constituency Development Fund (CDF) strategic plan 2018-2022, (2017) pointed that 75\% of the MSMEs operating in the Kitengela town depend mostly on mobile money services in transaction of their business. The current study sought to bridge this gap by investigating the relationship between mobile money services and performance of MSMEs in Kenya, Kitengela, Kajiado County. The study objectives were to establish the relationship between mobile payments and performance of Micro, Small and Medium Enterprises and to determine the influence of mobile money transfer on performance of Micro, Small and Medium Enterprises in Kenya, Kitengela, Kajiado County. The study was grounded by guided Diffusion of innovation theory. The study employed descriptive research design. The target population was 817 formally registered MSMEs in Kitengela Town dealing in trade, services and manufacturing. The study employed Fisher Model to come up with sample size of 261. The study relied on primary data which was collected using questionnaires. Quantitative data was presented in frequency tables and figures while quantitative data was presented in prose form. Multiple-regression was used to test the relationship between the independent variables and dependent variable. The study results shows that mobile money payment and mobile money transfer with $\mathrm{R}^{2}=0.559$ which means that around $60 \%$ of the performance of MSMEs in Kitengela town is influences by mobile money payment and mobile money transfer. Mobile money payment and mobile money transfer had a significant positive linear relationship of $\mathrm{R}=0.748$ between mobile money payment and mobile money transfer on the performance of MSMEs in Kitengela, Kajiado County. The results also indicated that the overall influence of mobile money payment and mobile money transfer on performance of MSMEs in Kitengela, Kajiado County was significant $(\mathrm{F}=254.658, \mathrm{p}<0.05)$. The study established that disbursement and repayment of loans influence mobile money transfer performance. The study concluded that mobile commerce had a statistical significance relationship with the performance of MSMEs in Kenya. The study therefore recommended that mobile services provider should seek to promote their services to encourage as many businesspeople as possible to make use of mobile money services.
\end{abstract}


Keywords: Micro Small and Medium Enterprises; Mobile Payments; Mobile Money Transfer; Performance.

\subsection{Introduction}

Across the world, the number of registered mobile users in 2019 reached 1.04 billion and close to $\$ 2$ billion in daily transactions with mobile money services being used across all sectors in the world (GSMA, 2019). Originally a product for a few selected markets, mobile money is now a global phenomenon, recording astonishing growth in emerging markets and reaching a broad range of customers (GSMA, 2019). For the first time in 2019, digital transactions represented the majority of mobile money flows, and more value is circulating in the mobile money system than exiting.

Despite the significant projection and growth of mobile money services across the globe, SubSaharan Africa remained enduring epicenter of mobile money service, adding over 50 million registered accounts in 2019. This was driven by strong growth in Western Africa (21 million new accounts) and Central Africa (6 million new accounts), as well as steady growth in Eastern Africa (22 million new accounts). The GSMA forecasts that account adoption across SubSaharan Africa will remain strong and that the region will surpass the half billion mark by the end of 2020 (GSMA, 2019). Across the world, Sub-Saharan Africa is the leading continents that conduct most of its money transaction through mobile money services. WB (2018) indicated that at least $(45.6 \%)$ of the mobile money activity conducted across the world happens within the Africa continent with approximately $\$ 26.8$ billion in transaction value in 2018 alone while this figure excludes bank operated solutions.

Mobile money services have been defined as electronic money accounts that can be accessed via mobile phone (Zutt, 2016). The mobile money transfer (MMT) service is an aspect of a broader concept emerging in the electronic payment and banking industry referred to as Mobile Money. Even though mobile money has not been well defined in literature it can be said to include all the various initiatives (long-distance remittance, micro-payments, and informal air-time battering schemes) aimed at bringing financial services to the unbanked using mobile technology. However, Mobile Money can be defined as money that can be accessed and used via mobile phone (Jenkins, 2008). Mobile money services offer secure and convenient means for banked and unbanked people to send and receive money with mobile phones at home and abroad, anywhere at any time. It contains features such as mobile wallet, mobile transfer, airtime 
transfers and mobile banking. Mobile wallet enables the subscriber to receive, store, send or pay money anywhere any time. Money transfer options means that one can send money from their mobile money account to a different subscriber anywhere anytime, which is similar to airtime transfer, where one can purchase and send airtime to another subscriber within the same network. Mobile banking works closely with banks to provide banking services to subscribers of mobile money.

In East Africa, the cradle of mobile money, the number of active mobile money accounts exceeded 100 million. However, the success of mobile money is no longer limited to a few markets and regions. The total number of accounts active monthly has exceeded 261 million, and the GSMA forecasts that by 2025 , the number of monthly mobile money customer accounts will surpass 370 million, the level where 90-day accounts were at end of 2019. Kenya has the leading number of users of mobile money services in the East African countries with 17,800,000 registered users, which represents $71.3 \%$ of the total number of mobile phone users in the country. Followed by Tanzania, which has 9,200,000 users of mobile money, representing 43.4\% of the total number of mobile phone subscribers in the country. Uganda has the third largest number of mobile money users in the East African region with 2,100,000 users representing $8.1 \%$ of the total number of mobile phone subscribers. Rwanda and Burundi have 309,127 and 29,000 users of mobile money services representing $8.3 \%$ and $2.7 \%$ of the total number of mobile phone users in those countries respectively (GSMA, 2017).

In Kenya, micro-business enterprises have increasingly deployed the use of mobile payments to enhance the quality of their services and increase growth. The pace of transformation in the micro business sector has speeded up with more micro businesses realizing the potential of using the mobile payments in their service delivery (Mbogo, 2010). Additionally, Kendall, Lyon, and Higgins (2012) pointed that Kenyan SME owners use mobile money services to pay utility bills or salaries or suppliers, they are driving higher volumes of both MM adoption and transactions. Ngaruiya (2014) indicated that the inception of mobile phone financial transaction has brought a lot of benefits to MSMEs. It has made money transfer to be available at a low cost compared to the traditional banking system where some transactions would be done within the premises of the bank. 
Despite their significance, past statistics indicate that three out of five businesses fail within the first few months of operation (Kenya National Bureau of Statistics, 2016). One of the main reasons for this failure is lack of financial inclusion, financial deepening, and lack of cash flow. To cope with financial challenges, SME owners have innovatively responded to changing market dynamics by adopting innovations in their firms aimed at maximizing on their returns, minimize costs as well as enhancing their business performance. One of such innovative model that they have adopted is the mobile money services that are easily available from the telecommunication firms such as M-pesa from Safaricom and Airtel money from Airtel which are major mobile money service providers.

In most Micro, Small and Medium Enterprises (MSMEs), are now using M-pesa to buy goods and make payment from their suppliers. These mobile money services include cashless distribution where fast-moving consumer goods (FMCG) companies. Person to person (P2P) money transfers, cash in deposits and cash out withdrawals at M-pesa agents, consumer to business (C2B) payments, business to consumer (B2C) payments and international money transfers are a common aspect mobile money services used in MSMEs, those in Kitengela included. Mobile-phone banking, mobile payments commonly known as "Lipa na M-pesa" and agent banking for instance are common aspects of these firms. However, the effect this adoption has had on their performance has remained unclear.

\subsection{Statement of the Problem}

Many governments through different organization continue to encourage the growth of small business as they form the backbone of the economic growth in any country. Compared to large enterprises, MSMEs face many unique challenges such as reluctance by commercial banks to meet their financial needs like payment and transactional services. This is attributed to their financial positions that do not permit them to qualify for financial supports such as loan as they possess low capital base and lack of security to secure the loan. MSMEs are often seen to process large numbers of payments and can have a surprising amount of money flowing through them. At the same time, their need for payment and transactional services are not always well served by traditional banks. They do not always find it easy or cost effective to adopt a full-featured package of banking services as a larger business might. 
According to Higgin at el (2012) lack of proper mode of receipts and payments, debt collection procedures and access to finance, makes MSMEs to be faced with problems associated with liquidity and working capital management. According to a survey carried out by the Kajiado East Constituency development fund and contained in a document titled Kajiado East Constituency Development Fund (CDF) strategic plan 2018-2022, (2017) pointed that 75\% of the MSMEs operating in the Kitengela town depend mostly on mobile money services in transaction of their business. The report stated failure of the banks to support and meet the need of the MSMEs in the area as the main reason to rely on mobile services offered by the telecommunication firms which enhance their performance. This phenomenon possesses a negative effect on performance of MSMEs. The introduction of mobile money services has reconfigured how MSMEs conduct their business. This innovation provided an ample and business friendly platform that eases financial transaction among the customer ad business as well as providing saving avenue and loans for unbanked business owners.

Local studies done include; Mbogo (2010), Ngaruiya (2014) and Mararo (2018). Despite the contribution of mobile money services in business, no study has been conducted in Kitengela to establish its contribution to MSMEs performance. Given the background of this study, no study has focused on Kitengela perspective, thus the current study sought to bridge this gap by investigating the relationship between mobile money services and performance of MSMEs in Kitengela, Kajiado County.

\subsection{Study Specific objectives}

i. To establish the relationship between mobile payments and performance of Micro, Small and Medium Enterprises in Kitengela, Kajiado County.

ii. To determine the influence of mobile transfer on performance of Micro, Small and Medium Enterprises in Kitengela, Kajiado County.

\subsection{Scope of the Study}

The objective of this study was to establish the relationship between mobile money services and performance of small and medium enterprises in Kitengela, Kajiado County. This study was undertaken between October and April 2021 at MSMEs in Kitengela, Kajiado County targeting 261 MSMEs owners. 


\subsection{Literature Review}

\subsection{Theoretical Literature Review}

The study was guided by the Diffusion of innovation theory (DIT) and Technological Acceptance Model (TAM) theories.

\subsubsection{Diffusion of Innovation Theory}

The diffusion of innovation theory was first coined by Rogers in 1962. This was after Rogers carried out a research on the innovations. The theory holds that an idea that is related to the product nature and how it's perceived gives the underlying momentum for the innovation initiatives and allows for the diffusions and the spreading of the ideas which is therefore adopted among a given population or the related social structure (Rogers, 1995). The actual result of the diffusion activities is that people are motivated to adopt the new ideas given that people are part of the social structure. The theory further postulates that there are fundamental factors behind the adoption of the new ideas which includes the perception that people have towards the new idea and their collective behavior influences on the diffusion and acceptance of the new innovations (Rogers, 1995).

Li and Atuagene-Gima (2011) who is a key proponent to the theory, states that in its attempt to explain and give descriptions on how new ideas are spread and adopted, the diffusion theory puts across five fundamental factors to explain the basis of this process. The factors are considered to play a key fundamental role. Complexity, trial ability, competitive advantages, observability, and compatibility have been identified as some of the factors that aid the adoption of the theory (Rogers, 1995). The application of the diffusion of innovation theory has been considered significant in understanding and comprehending the changes that do take place in the adoption and the use of mobile money services among the small and medium enterprises (Rogers, 1995). There are significant factors that therefore play a key pivotal role in the adoption of mobile technologies. Further the decision to adopt a new technology depends on the personal views of the individuals and the organizational perspective with respect to the use of the mobile money transaction services among the small and medium enterprises. Small and medium enterprises are likely to remain competitive in the market based on their average performance on the technological capacity (Rogers, 1995). 


\subsubsection{Technological Acceptance Model (TAM)}

The technological acceptance model (TAM) is one of the anchoring theories that have been adopted by the current study. The theory was first coined by Davis in 1989. According to Davis, the theory applies to any human-computer interactions without being specific on the aspects of interactions (Davis, 1989). The theory asserts that perceived usefulness and the perceived ease of use determine the need associated with the technological adoption among the users. Further the proponents of the theory holds that the key determinants and antecedents of the interactions and behavioral motivations to adopt the new technological is primarily guided by the perceived ease of use of the new technological ideas (Sun, 2006). Therefore, the theory presents the major determinants that motivate the adoption of the new technological ideas (Davis, 1989).

The application of the TAM theory has been considered significant to this study taking into consideration, the view that technological attitudes have been significant in influencing the use of mobile technology among the MSMEs in Kenya (Sun, 2006). Zang (2008) holds that there are psychological perspectives that are perceived in the mobile communications which relates to people's perceptions, attitudes and expectations and further determines the perceived characteristics that determines on the choice of communication channels among the small and medium enterprises (Sun, 2006). The theory was also significant to the study since it points to the other external factors outside the business environment that also effects on the adoption and use of the mobile technologies among the small and medium enterprises.

\subsection{Empirical Literature review}

\subsubsection{Mobile Money Payments and Performance of MSMEs}

There are a number of research papers that have documented the use of mobile money payments on the performance of the small and medium enterprises. Studies have revealed that the concept of the mobile payments which refers to the various mobile applications methods through which users are able to make money transaction through business to business or business to customer modules (Fanta, 2016). The studies revealed that the use of the mobile phone payment methods have resulted in the reduced-price variations in the business market significantly therefore reducing the overall costs of doing business (Batista, 2020). The mobile payments methods involve all the transactions that deal with the withdrawals, the processes of making deposits and 
applications for loans through utilizations of the mobile phone services (Fanta, 2016). Several studies have been done internationally, regionally, and locally.

Tat (2018) did a study on the opportunities and challenges of the mobile payment services in Sweden. The main objective of the study was to broaden the knowledge and the understanding about the ways mobile payment service providers address the opportunities and challenges of mobile payment services. In order to investigate the problem, the study explored factors stimulating and hindering the introduction of mobile payments using perspectives of different types of service providers which included the banks, independent providers, direct operator billing providers, retailers, and public transport companies and also to seeks to explain the importance of these factors for each type of provider (Tat, 2018). The primary data for the study was collected using the interview method where more than 40 industry representatives in six countries were contacted. The Service, Technology, Organization, and Finance (STOF) model was used as a theoretical research framework. The study findings revealed that the organization domain is the key domain, which affects all other domains and has an impact on the general viability of the business model (Tat, 2018).

Ngaruiya (2014) did a study on the effects of the mobile payment transactions on the financial performance of MSMEs in Nakuru central business district (Ngaruya, 2014). The study revealed that the inception of mobile phone payment transaction has brought a lot of benefits to SME in Kenya. It has made money transfer to be available at a low cost compared to those traditional banking systems where some transactions are done within the premises of the bank. The aim of this study was to find out the effect of mobile money transactions on financial performance of MSMEs in Nakuru town central business district (CBD). The study made the use of the descriptive research design, where it sampled 120 out of 640 businesses with the use of the purposive sampling technique. The data collection for the study was done using the questionnaire method as the main data collection instrument. The results of the study revealed that mobile money transactions have a significant effect on the sales revenue (Ngaruya, 2014).

Mbogo (2017) did a study on the impact of mobile payments on the success and growth of micro-business, a case of M-pesa in Kenya. The study aimed at investigating the success factors 
attributable to the use of mobile payments by micro-business operators, based on a survey conducted through administration of questionnaires. The data was collected from a sample of 409 micro business entrepreneurs in Nairobi, Kenya. The study made use of the TAM model, which it extended to include other factors to help in predicting the success and growth in microbusinesses (Mbogo, 2017). Analyses of the data reveal that convenience of the money payments technology plus its accessibility, cost, support and security factors are related to the behavioral intention to use and actual usage of the mobile payment services by the micro businesses to enhance their success and growth. The study also revealed that the pace of transformation in the micro business sector has speeded up with more micro businesses realizing the potential of using the mobile payments in their service delivery (Mbogo, 2017).

\subsubsection{Mobile Money Transfers and Performance of MSMEs}

Mobile money transfer refers to the approaches and methods that allow the users of the mobile money services to transfer funds through their mobile phone through the text messaging. The use of the mobile money transfer has gained a tremendous phenomenon growth (Fanta, 2016). The efficiency and affordability associated with the use of the mobile money transfer is a significant financial breakthrough that every person requires. The use of the mobile transfers has been regarded as the most efficient way of carrying out transaction and has been adopted by vast majority of people in businesses (Batista, 2020). The existence of the mobile phone coverage through provisions of the mobile transfer services has promoted the consumptions of the mobile transfers' services which has made the services to be reliable and effective. With the increase in the uptake of these mobile money transfer services, majority of the MSMEs have enrolled and are utilizing these services in their trading activities (Batista, 2020). Several studies have been done locally, regionally, and internationally.

Talom and Tengeh (2020) conducted a study on the Impact of Mobile Money on the Financial Performance of the MSMEs in Douala, Cameroon. The research method that was adopted for this was a qualitative/descriptive method. The information collected was summarized to leave space for interpretations and discussions. And through the study it was imperative that the objectives of the study should not in any way be overlooked. The overall objective of the research was to investigate the impact of mobile money services on Small and Medium 
Enterprises (MSMEs). The sample for the research comprises of MSMEs in Limbe, Blantyre, Malawi. The choice for MSMEs in Limbe was arrived it was reasonable for the budget of the researcher. This is a municipality in the heart of Blantyre. This research was not conducted to compare the mobile operators as to which are most respondents subscribed to, so the collected information was not sort in any way to render the research favorable to one network than the other. Through the study some concerns were found that made for the most of the recommendations and conclusions that were addressed to both parties involved in the study like that of convenience, reliability of the services and some security concerns.

Mutinda (2018) did a study on the effect of mobile phone-based money transfers on the financial performance of small and medium enterprises in Nairobi County. The study adopted descriptive survey method. A target population of more than 50,000 formally registered MSMEs was used and total sample size of 460 respondents was picked as representative giving a provision of $20 \%$ over and above the desired sample size in the event of non-response on some of the respondents in the sample size. The desired sample size was derived using Mugenda and Mugenda (2003) recommendation. Stratified sampling was one of the probability techniques used in order to ensure that various types of MSMEs were included in the survey. Data was collected using selfadministered questionnaires and interview guide. The collected data was analyzed using Statistical package for Social Scientist software. The results of the study were analyzed using descriptive and inferential statistics and the results were presented using figures and tables. The findings of the study revealed that there is a positive correlation between MSMEs financial performance and business growth, efficiency in service delivery, access to information and convenience and reliability. Development of mobile money transfer services influences the development of market; mobile money transfer services enhance efficiency in service delivery in business; access to information in mobile money transfer services depend on the environment and mobile money transfer services are convenient and reliable.

\subsection{Conceptual Framework}

A conceptual framework is a written or virtual product that explains, either in narrative or in graphically form, the main things to be studied, the key elements being variables, concepts and the presumed relationships among them. A conceptual framework is structured from a set of broad theories and ideas that help a researcher in properly identifying the problem they are 
looking at, frame their research questions and find suitable literature. Therefore, in regards to this framework, the independent variables are mobile payments and mobile money transfer while dependent variable is performance of MSMEs.

Independent Variables

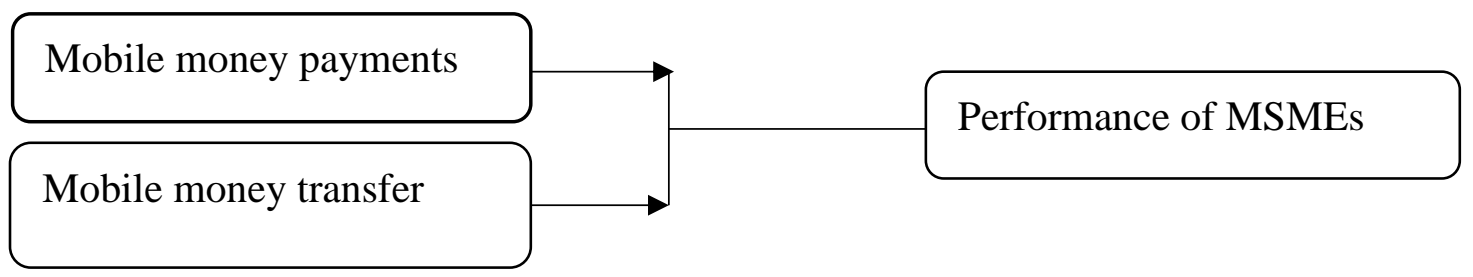

\section{Figure 2.1 Conceptual Framework}

\subsection{Research Methodology}

\subsection{Research Design}

Research design is an overall strategy deployed by a researcher in order to integrate the different components of a study into a coherent and logical flow. An adequate research design ensures that the research problem is precisely addressed. In this study, a descriptive survey research design shall be adopted. Kothari (2008) noted that deploying a descriptive survey enables a researcher to respond to the 'what' question. On the other hand, McNeil (2018) asserts that although descriptive research design inclines, majorly, towards qualitative techniques, quantifiable data is viable as well.

\subsection{Target Population}

Target population, according to Ngechu (2004), is a well-defined or set of people, services, elements, events, group of things or households that are being investigated. This definition ensures that population of interest is homogeneous. . The target population of this study were the proprietors of the micro, small and medium enterprises Kitengela dealing in both trade and services. According to Kajiado East Constituency development fund (2018), there are 817 formally registered Small and Medium Enterprises Kitengela Town dealing in trade, services, and manufacturing.

\subsection{Sample Population}

The sampling frame for any probability sample is a whole list of entire cases in the population from which sample is derived (Cooper, 2003). The sample frame clearly defined as informal 
traders in this study are all MSMEs operating in Kitengela township. In order to come up with a representative sample of the target population for this study, we proposed to use the Modified Fisher Model since the population is less than 10,000. Given that the population of interest for the study was 817 (population size $\mathrm{N}=817$ ), the corrected sample size was obtained as illustrated mathematically using Modified Fisher's Model as below:

Equation 1: $\mathrm{nf}=\frac{\mathrm{n}}{1+\frac{(\mathrm{n}-1)}{\mathrm{N}}}=384 /[1+(384 / 817)] ; \mathrm{n}=261$

\subsection{Data Collection Procedure}

The primary data was collected through employing of a questionnaire. The feelings, motivations, attitudes, accomplishments, and experiences of individuals are inquired through questionnaire's and that why it is appropriate for the collection of information (Mellenbergh, 2008). The study's questionnaire captured the objectives of the study and the researcher also ensured that the participants were not manipulated as stated by Franker, (2006). Which were distributed with the help three other assistants who were involved by the researcher. The drop and pick later method was used in administering of the questionnaires. The questionnaire adopted a Likert scale questions ranging from 1 to 5 in the 5-point Likert scale, to measure the level of the respondent agreement to specific constructs used to measure the independent variables and dependent variable adopted in this study (Kiess \& Bloomquist, 2008).

\subsection{Data Analysis and Presentation}

The Statistical Packages for Social Scientists (SPSS Version 24.0) was used to code and enter the quantitative data and descriptive statistics were used in analyzing the data. The study also used inferential statistics to establish relationship between mobile money services and performance of small and medium enterprises. Further, to establish the strength of the relationship between the independent and dependent variables the researcher used multiple regressions.

The regression equation is:

$\mathbf{Y}=\boldsymbol{\beta}_{0}+\boldsymbol{\beta}_{1} \mathbf{X}_{1}+\boldsymbol{\beta}_{2} \mathbf{X}_{2}+\varepsilon$

Where: $\mathrm{Y}$ is the dependent variable (Performance of MSMEs); $\beta_{0}$ is the regression coefficient; $\beta_{1}$ and $\beta_{2}$ are the slopes of the regression equations; $X_{1}$ is Mobile payment; $X_{2}$ is Mobile transfer; $\varepsilon$ is an error term normally assumed to be 0 . 


\subsection{Data Analysis, Presentation and Interpretation}

\subsection{Study Response Rate}

The study targeted a total of 261 formally registered Small and Medium Enterprises Kitengela Town dealing in trade, services, and manufacturing. However, out of the 261 targeted Micro, Small and Medium Enterprises Kitengela Town, the researcher was only able to obtain complete data for 203 Small and Medium Enterprises Kitengela Town representing a response rate of $78 \%$. The response rate of $78 \%$ was deemed sufficient for the purpose of data analysis as Mugenda and Mugenda (2003) notes that a response rate of 50\% is adequate for analysis and reporting, $60 \%$ is good and a response rate of $70 \%$ and over is excellent.

Table 4.1 Study Response Rate

\begin{tabular}{lcc}
\hline Response & Frequency & Percentage (\%) \\
\hline Filled in questionnaires & 203 & 78 \\
Unreturned questionnaires & 58 & 22 \\
\hline Total & $\mathbf{2 6 1}$ & $\mathbf{1 0 0}$ \\
\hline
\end{tabular}

\subsection{Reliability Results}

The research instrument's reliability was tested through the Cronbach Alpha. The rule of thumb is that a Cronbach's alpha of 0.70 and above is good, 0.80 and above is better and 0.90 and above is best and reflects a high level of internal consistency (Sekaran, 2003). This was the general case in this pilot study where all the predictor variables and the response variable had alpha values of 0.70 and above as indicated in table 4.2. This was the general outcome in this pilot study where all the predictor variables and the response variables had alpha values of 0.70 and above as indicated in table 4.2. All the variables used in this study were found to be reliable since their Cronbach's alpha value exceeded 0.70

Table 4.2 Reliability Results

\begin{tabular}{lcccc}
\hline Variable & $\begin{array}{c}\text { No. of } \\
\text { Respondents }\end{array}$ & $\begin{array}{c}\text { No. of } \\
\text { Items }\end{array}$ & $\begin{array}{c}\text { Cronbach's } \\
\text { Alpha }\end{array}$ & Verdict \\
\hline Mobile payments & 26 & 4 & 0.748 & Reliable \\
Mobile transfer & 26 & 5 & 0.711 & Reliable \\
\hline
\end{tabular}

\subsection{Gender of the Respondents}

The study sought to establish the gender of the respondents who participated in the study. According to the study results that were obtained, it was found out that a slight majority $52 \%$ of 
the respondents were male while $48 \%$ were females. The study results suggest that most of the MSMEs operators in Kitengela town, Kajiado County are male though their female counterparts are well represented as well as shown in figure 4.1.

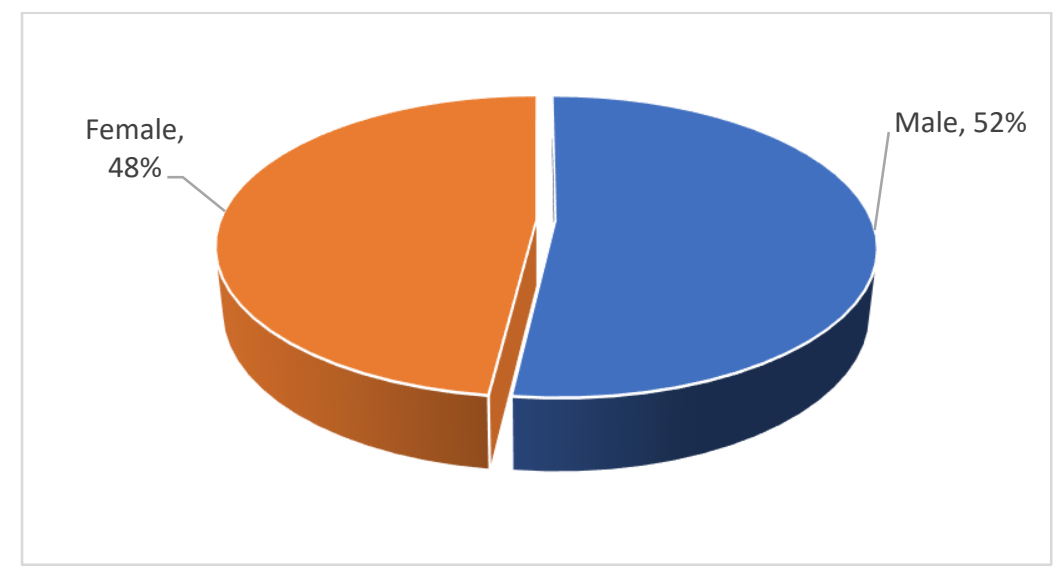

Figure 4.1: Gender of the Respondents

\subsection{Mobile Money Services Usage}

Respondents were further requested to indicate whether their business enterprises used mobile money services. In accordance with the study findings that were obtained, it was established that $94 \%$ of the respondents indicated that they used mobile money services while only $6 \%$ who indicated that they didn't use mobile money services at their business enterprises.

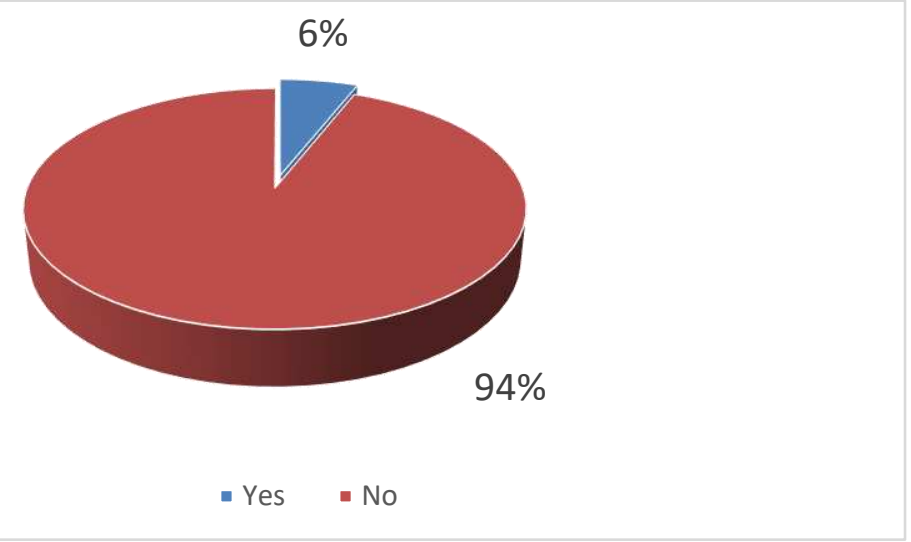

\section{Figure 4.1: Mobile Money Services Usage}

\subsection{Mobile Money Services Usage}

Respondents were further requested to indicate whether their business enterprises used mobile money services. In accordance with the study findings that were obtained, it was established that $94 \%$ of the respondents indicated that they used mobile money services while only $6 \%$ who indicated that they didn't use mobile money services at their business enterprises. 


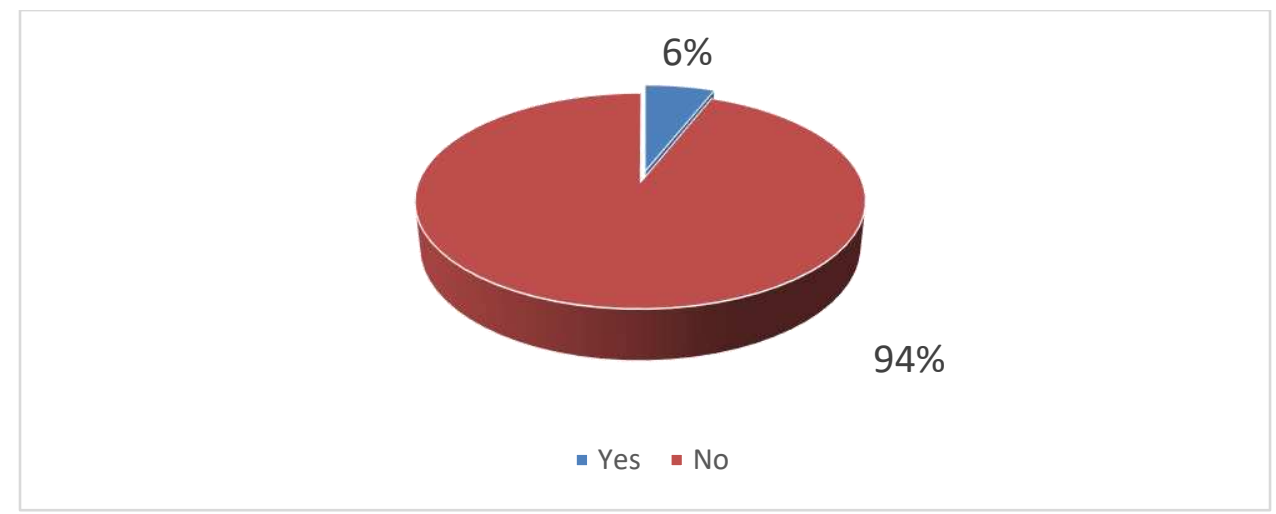

Figure 4.2: Mobile Money Services Usage

\subsection{Descriptive analysis}

\subsubsection{Mobile Money Transfer and Performance of MSMEs}

Respondents were requested by the researcher to indicate their level of agreement in regards to the influence of mobile money transfer on performance of MSMEs. According to the study results that were obtained, it was found out that to a great extent disbursement and repayment of loans influence mobile money transfer performance as indicated by the mean score of 3.96 . These findings concur with those of Arnold (2017) that business have adopted mobile services see it as an efficient way of collecting dues, and banks use it as a good avenue way to mobilize deposits, disburse loans and receive loan repayments. Respondents also agreed to a large extent that cash transfers influence mobile money transfer performance as indicated by the mean score of 3.86. The findings are consistent with those of Cook and McKay (2017) who observed that an increasing number of business peoples do not necessarily need to physically visit a financial institution to deposit money, receive a loan, make a payment or transfer funds since mobile money services has provided a platform to access financial services easily. In addition, respondents to a large extent agreed that $\mathrm{P} 2 \mathrm{P}$ transfers have influenced mobile money transfer performance as shown by the mean score of 3.72. The findings agreed with those of Kiprono (2018) that mobile money platforms were largely used for person-to-person (P2P) cash transfers, they are now increasingly being used to purchase of goods, processing of instant short-term loans as well as making payments for government services. Respondents further moderately agreed that buy business goods and buying airtime activities have greatly enhanced performance of MSMEs as depicted by the mean scores of 3.61 and 3.51 respectively. In study that was conducted by Oromo (2015) pointed that mobile money services have been a significant driver of 
change in the way businesses function, supplementing bank services such as money transaction and deposit, among others.

Table 4.3: Mobile Money Transfer and Performance of MSMEs

\begin{tabular}{lcc}
\hline Statement & Mean & STDev \\
\hline P2P transfers & 3.72 & 0.16 \\
Disbursement and repayment of loans & 3.96 & 1.21 \\
Cash transfers & 3.86 & 1.15 \\
Buying airtime & 3.51 & 1.42 \\
Buy business goods & 3.61 & 1.16 \\
\hline
\end{tabular}

\subsubsection{Mobile Money Payments and Performance of MSMEs}

The study sought to establish the effect of mobile money payment on the financial performance of MSMEs. The study results that were obtained indicated that respondents to a very great extent agreed that paying utility bills enhanced the performance of among MSMEs as indicated by the mean score of 3.70. This is consistent with a study conducted by Keynes (2017), which proved that mobile banking technology enables people to access financial services more conveniently, pay bills less expensively, and manage their money more efficiently. This means that micro entrepreneurs in the study area are able to devote their full attention to their operations due to the limited movement required to obtain banking services for bill payment.

In addition, respondents agreed to a very great extent that salary processing influenced the performance of mobile money services among MSMEs as indicated by the mean score of 3.62. According to UNCTAD (2017) from a small business viewpoint, mobile money transactions enable money transfers as well as merchant, bill, and salary payments. Further respondents agreed that to a great extent that supplier payments and value chain payments the performance of mobile money services among MSMEs as indicated by the mean scores of 3.44 and 3.34 respectively. This is in line with Keizers (2017) that mobile money enhance inclusion of unbanked and enable them MSEs to access the cash flow needed quickly and making payment to suppliers. 
Table 4.4: Mobile Money Payments and Performance of MSMEs

\begin{tabular}{lcc}
\hline Statement & Mean & STDev \\
Salary processing & 3.62 & 1.37 \\
Pay utility bills & 3.70 & 1.31 \\
Supplier payments & 3.44 & 1.41 \\
Value chain payments & 3.34 & 1.36 \\
\hline
\end{tabular}

\subsubsection{Aspects of MSMEs Performance}

Respondents were requested to provide their level of agreement in regard to the following statement on the various aspects of MSMEs performance. According to the study results that were obtained, it was found out that respondents agreed to a very great extent that using mobile money services had enhanced their customers' satisfaction as indicated by the mean score of 3.962. The study was in line with Abong'o (2016) that there are positive results obtained from mobile money services in service quality such as customer satisfaction, less processing cost, profitability, and customer loyalty in most businesses. Likewise, respondents agreed that to a very great extent also agreed that using mobile money services had also increased their sales turnover as shown by the mean score of 3.915. According to findings by Donner and Escobari (2010) established that mobile phones have helped SMEs to become more productive and to improve their sales thereby improving their financial performance. Result by Wambari (2009) found a similar result that the adoption of mobile banking had enabled SMEs to increase their sales thereby leading to improved financial performance. Respondents to a large extent further indicated that using mobile money services had increased their revenue generation as well as their profitability as illustrated by the mean scores of 3.861 and 3.832 respectively. In a study conducted by Ngaruiya, B. (2014) pointed that after the adoption of mobile money financial transactions, majority of the SMEs have reported an increased sales revenue. Lastly, respondents to a moderate extent agreed that using mobile money services had increased their market share as indicated by the mean score of 2.944. the findings conform to Jensen (2017) mobile financial transactions provide SMEs with a means through which they can reduce their operating costs as well as increase their ability to extend their business networks thus enabling them to increase their performance. 
Table 4.5: Performance of MSMEs

\begin{tabular}{lcc}
\hline Statement & Mean & STDev \\
Sales turnover & 3.915 & 0.832 \\
Market share & 2.944 & 0.723 \\
Revenue generation & 3.861 & 1.151 \\
Profitability & 3.832 & 0.851 \\
Customer satisfaction & 3.962 & 1.206 \\
\hline
\end{tabular}

\subsection{Inferential Analysis}

To compute the correlation between dependent variable and the independent variables the study conducted inferential analysis.

Coefficient of determination $\left(\mathrm{R}^{2}\right)$ explains the extent to which changes in the dependent variable can be explained by the change in the independent variables or the percentage of variation in the dependent variable (performance of MSMEs) that is explained by all the two independent variables (mobile money payment and mobile money transfer). The two independent variables that were studied, explain only $56 \%$ of the performance of MSMEs in Kitengela town as represented by the adjusted $\mathrm{R}^{2}=0.559$. This therefore means that there are other factors not studied in this research that contribute $44.1 \%$ of the performance of MSMEs in Kitengela town. Therefore, further research should be conducted to investigate the other (44.1\%) mobile money services which tend to influence the performance of MSMEs in Kitengela town.

Table 4.6: Model Summary

\begin{tabular}{lllll}
\hline Model & R & R Square & Adjusted R Square & Std. Error of the Estimate \\
\hline 1 & .748 & 0.559 & 0.557 & 0.26195
\end{tabular}

The analysis of variance (ANOVA), as shown in Table 4.7 demonstrates the regression model's relevance. The significance of the variance explained by the regression model is determined using ANOVA in this model. The analysis of variance's F-statistic is 254.658 with a p-value of 0.000 . The $\mathrm{p}$-value is less than 0.05 , indicating that the parameters of the model predictors are not jointly equal to zero in a significant way. This indicates that at least one of the model's predictors has a significant parameter, implying that the model's predictors (mobile money services variables) have a cumulative effect on the performance of MSMEs in Kenya. 
Table 4.7: Model Summary

\begin{tabular}{llccccc}
\hline \multicolumn{1}{l}{ Model } & Sum of & & & & \\
\hline 1 & Regression & Squares & df & Mean Square & F & Sig. \\
\hline & Residual & 17.474 & 1 & 17.474 & 254.658 & .000 \\
& Total & 13.792 & 201 & .069 & & \\
\hline
\end{tabular}

a. Dependent Variable: performance of MSMEs

b. Predictors: (Constant), mobile money payment, mobile money transfer

Table 4.8: Regression Coefficients

\begin{tabular}{lccccc}
\hline & \multicolumn{2}{c}{$\begin{array}{c}\text { Unstandardized } \\
\text { Coefficients }\end{array}$} & $\begin{array}{c}\text { Standardized } \\
\text { Coefficients }\end{array}$ & & \\
Model & B & std. Error & Beta & t & Sig. \\
\hline (Constant) & 1.308 & 0.342 & & 1.623 & $3.57-02$ \\
Mobile Money Payment & 0.558 & 0.310 & 0.172 & 4.342 & $2.76-02$ \\
Mobile Money Transfer & 0.731 & 0.156 & 0.210 & 3.532 & $2.85-02$ \\
\hline
\end{tabular}

As per the SPSS results in the table above, the following multiple regression equation was generated:

$$
\begin{aligned}
& \left(\mathbf{Y}=\boldsymbol{\beta}_{\mathbf{0}}+\boldsymbol{\beta}_{1} \mathbf{X}_{\mathbf{1}}+\boldsymbol{\beta}_{2} \mathbf{X}_{\mathbf{2}}+\boldsymbol{\varepsilon}\right) \\
& Y=1.308+0.558 \mathrm{X}_{1}+0.731 \mathrm{X}_{2}
\end{aligned}
$$

The regression equation above established that taking all factors into account (mobile money payment and mobile money transfer) constant at zero, performance of MSMEs will be 1.308. The findings presented also shows that taking all other independent variables at zero, a unit increase in mobile money payment will lead to a 0.558 increase in performance of MSMEs; a unit increase in mobile money transfer will lead to a 0.731 increase in performance of MSMEs. This infers that money transfer services contribute most towards performance of MSMEs followed by mobile money payment towards performance of MSMEs. This notwithstanding, all the variables were significant as their P-values were less than 0.05 .

\subsection{Summary, Conclusion and Recommendation}

\subsection{Summary of Research Findings}

The first study objectives sought to examine the relationship between mobile money transfer and the performance of MSMEs in Kitengela town. According to the study results that were obtained, 
it was established that disbursement and repayment of loans influence mobile money transfer performance to a very large extent. In addition, it was found out that cash transfers influence mobile money transfer performance also to a very large extent.

The second study objective sought to examine the relationship between mobile money financial services and the performance of MSMEs in Kitengela town. According to the study results that were obtained, it was established that sending money influenced the overall performance of mobile financial services to a very large extent. Also, withdraw of money from mobile phone have enhanced the overall performance of mobile financial services to a very large extent.

Further the study results shows that mobile money payment and mobile money transfer with $\mathrm{R}^{2}=0.559$ which means that around $60 \%$ of the performance of MSMEs in Kitengela town is influences by mobile money payment and mobile money transfer. Mobile money payment and mobile money transfer had a significance of $\mathrm{P}<0.00$ which is less than 0.05 , hence, it was clear that there was linear relationship $\mathrm{R}=0.748$ between mobile money payment and mobile money transfer and the performance of MSMEs in Kitengela, Kajiado County. The results also indicated that the overall influence of mobile money transfer on performance of MSMEs in Kitengela, Kajiado County was significant $(\mathrm{F}=254.658, \mathrm{p}<0.05)$.

\subsection{Conclusion}

On the objective on the relationship between mobile money transfer and the performance of MSMEs in Kitengela town, the study concluded that disbursement and repayment of loans influence mobile money transfer performance to a very large extent. The study also concluded that cash transfers influence mobile money transfer performance also to a very large extent. It was also concluded that there was linear relationship between mobile money transfer and the performance of MSMEs in Kitengela, Kajiado County.

On the objective on the relationship between mobile money payments and the performance of MSMEs in Kitengela town, it was concluded that paying utility bills influenced the performance of mobile money services among MSMEs in Kitengela, Kajiado County. It was also concluded that salary processing and supplier's payment influenced the performance of mobile money services among MSMEs in Kitengela, Kajiado County. The study further concluded that there was linear relationship between mobile money payment customer and performance of MSMEs in Kitengela, Kajiado County. 


\subsection{Recommendations}

The study recommended that that the mobile services provider should seek to promote their services so as to encourage as many business persons as possible to make use of mobile money services. This can be done through consistent advertisements that will serve as a constant reminder of the importance of mobile money services to the operations of their business. On the other hand, MSMEs should take advantage of the increase in use of mobile money services to form collaborations with mobile phone services providers and provide flexible mobile money services to MSMEs.

The study also recommended that MSMEs should adopt mobile money services in their businesses as this has been shown to serve as an instrument of growth in business. The use of mobile money services has been shown to have many potential benefits including shielding the traders from theft as a result of having so much cash at hand. MSMEs is a large and growing sector that employs a large number of our population, and the use of mobile money services aids in achieving both immediate and long-term goals.

\section{References}

Abdil. S. (2011). The relationship between the mobile financial innovations and the performance of the MSMEs in Sweden- 1(3): 273-288.

Keizers, B. W. G. (2017). Determinants of cash holdings for Dutch SME's (Bachelor's thesis, University of Twente).

Ngaruiya, B. (2014). Effects of mobile money transactions on financial performance of small and medium enterprises in Nakuru central business district (Doctoral dissertation, Egerton University).

Abong'o, M. O. (2016). Service Quality and Competiveness in Mobile Money Firms (Doctoral dissertation, University of Nairobi).

UNCTAD. (2017). Mobile Money for Business Development in the East African Community: A Comparative Study of Existing Platforms and Regulations.

Njabu, I. T. (2016). The impact of the Mobile Money Services on the Growth of Micro, Small and Medium Enterprises in Nkasi District Council (Doctoral dissertation, Master's Thesis, Mzumbe University, Nkasi, Tanzania.

Opare, E. A. (2018). The advantages and disadvantages of Mobile Money on the profitability of the Ghanaian banking industry. Texila International Journal of Management, 4(2), 1-8.

Mararo, M. W. (2018). Influence of mobile money services on the growth of SME in Nakuru Town Kenya (Doctoral dissertation, JKUAT).

Cook, W., \& McKay, C. (2017). Banking in the M-PESA age: lessons from Kenya. Work. Pap. Washington, DC CGAP.

Oromo, M. A. (2015). The relationship between mobile money and loans issued by commercial banks in Kenya, Unpublished MSC project, University of Nairobi. 
Kiprono, G. (2018). Effect of Mobile Money Innovations on the Financial Performance of Commercial Banks in Kenya, Unpublished Doctoral dissertation, University of Nairobi.

Arnold, M. (2017). European banks to launch block-chain trade finance platform. Financial Times.

Li, H., \& Atuagene-Gima, K. (2011). Product innovation strategy and the performance of new technology ventures in China. Academy of Management Journal, 44(6): 1123-1134

Ban, S. (2011). The mobile money payments among the Micro business enterprises in Uganda, Doctoral dissertation, Kampala University.

Banangaki, N. (2018). Mobile money services and market performance of micro business enterprises a case study of Nakawa Municipality.

Batista, C. a. (2020). Adopting Mobile Money: Evidence from an Experiment in Rural Africa." AEA Papers and Proceedings, 110: 594-98.

Chale, P., \& Mbamba, U. (2015). The role of mobile money services on growth of small and medium enterprises in Tanzania: Evidence from Kinondoni district in Dares-Salaam region. Business Management Review, 17(1).

Mutio, F. M. (2019). Influence of Mobile Banking Services on Performance of Micro Businesses in the Informal Sector in Kenya: A Case Study of Jua Kali Artisans in Nairobi County (Doctoral dissertation, United States International University-Africa).

Chau, N. T., \& Deng, H. (2018). Critical determinants for mobile commerce adoption in Vietnamese MSMEs: a conceptual framework. Procedia computer science, 138(2) 433 440.

Cherono. (2018). The relationship between the Mobile money transfers and the business performance- 1(3): 273-288.

Davis. (1989). Perceived usefulness, Perceived ease of Use, and User Acceptance of Information Technology. MIS Quarterly, 319-340.

Fanta, A. B. (2016). The role of mobile money in financial inclusion in the SADC region. Evidence using Fin Scope surveys. Policy Research Paper No. 03/2016.

Fleischer, T. \&. (1990). Information And Management. A critial Review of the Technology Accepance Model, 191-204.

Harfoushi. (2016). Technological innovation and small firms: a taxonomy", International Small Business Journal, 9, 3.

Iravonga. (2018). effects of the Mobile financial services on the financial performance of the small scale and medium enterprises in Kakamega County; Kenya- 1(3):273-288.

Kabanda, D. K. (2014). The impact of mobile money services on the performance of the commercial banking sector in Uganda; A case study of MTN mobile money.

Karimi. (2016). the impact of the financial services and communications on the performance of small and medium enterprises in the selected units in Kenya. Unpublished Thesis UON

Kendall, J., Lyon, B., \& Higgins, D. (2012). Mobile money usage patterns of Kenyan small and medium enterprises. Available at SSRN 2116481.

Khaskheli, A., Jun, Y., \& Bhuiyan, M. A. (2017). M-commerce and mobile apps: opportunities for MSMEs in developing countries. Marketing, 2(2).

Khaskheli, A., Jun, Y., \& Bhuiyan, M. A. (2017). M-commerce and mobile apps: opportunities for MSMEs in developing countries. Marketing, 2(2).

Latour, C. A. (1981). The Digital Provide: Information (Technology), Market Performance and Welfare in the South Indian Fisheries Sector. Quarterly Journal of Economics, 122, 879 $-924$. 
Laura. (2014). Impact of the Mobile money transfers and usage on the microenterprises in Zambia-1(3), 273-288.

Lumu, E. (2017). Mobile money services and market performance of micro. Doctoral dissertation, Uganda Technology and Management University.

Madila. (2016). Effectiveness of the Mobile money financial applications on the development of the medium and small enterprises in Tanzania- 1(3):273-288.

Mararo, M. W. (2018). Influence of mobile money services on the growth of SME in Nakuru Town Kenya (Doctoral dissertation, JKUAT).

Marulanda. (2015). Mobile Conditional Transfers on the performance of the business in Columbia- 1(3): 273-288.

Masocha, R., \& Dzomonda, O. (2018). Adoption of Mobile Money Services and the performance of small and medium enterprises in Zimbabwe. Academy of Accounting and Financial Studies Journal, 22(3), 1-11.

Masocha, R., \& Dzomonda, O. (2018). Adoption of Mobile Money Services and the performance of small and medium enterprises in Zimbabwe. Academy of Accounting and Financial Studies Journal.

Mbogo, M. (2010). The impact of mobile payments on the success and growth of microbusiness: The case of M-Pesa in Kenya. Journal of Language, Technology \& Entrepreneurship in Africa, 2(1): 182-203.

Mbogo. (2010). Impact of the Mobile Payments on the success and the Growth of the MicroBusiness-The case of M-pesa in Kenya. 1(3): 273-288.

Mosocha, O. a. (2018). Adoption of mobile commerce services and the performance of the small and medium enterprises in Zimbabwe. European Journal of Business and Management, $3(7), 59-77$.

Muhammad. (2011). Adoption of Mobile Commerce Service among Employed Mobile Phone Users in Bangladesh: Self-efficacy as A Moderator. 320-333.

Mutinda, A. N. (2018). The effect of mobile phone based money transfers on the financial performance of small and medium enterprises in Nairobi County, Kenya (Doctoral dissertation, University of Nairobi).

Ngaruiya, B. (2014). Effects of mobile money transactions on financial performance of small and medium enterprises in Nakuru Central Business District (Doctoral dissertation, Egerton University).

Ngaruiya, B., Bosire, M., \& Kamau, S. (2017). Effect of mobile money transactions on financial performance of small and medium enterprises in Nakuru Central Business District. Research Journal of Finance and Accounting, 5(12), 53-58.

Ngaruya. (2014). the effects of the Mobile payments transactions on the financial performance of the small and Medium enterprises in Nakuru Central business District. MBA Project research paper. UON/2014.

Nripendra, R. a. (2019). exploring the barriers of m-commerce adoption in MSMEs in the UK$1(3), 273-288$.

Ntlatlapa, M. J. (2017). The determinants of mobile money adoption and usage: the case of Lesotho (Doctoral dissertation, University of the Free State).

Nyaga. (2013). mobile commerce services on the performance of the small and medium enterprises in the urban town in Kenya. 
Okolo, V. C., \& Obidigbo, C. (2014). Boosting small and medium enterprises performance in Nigeria through mobile commerce. European Journal of Business and Management, 6(9), 134-141.

Oloko. (2015). Mobile Money transfers and the growth of the small and medium sized enterprises in Kenya- 1(3):273-288.

Robertson, F. a. (2019). Impact of Mobile commerce on the Financial Performance of the MSMEs in Douala, Cameroon-320-333.

Rogers. (1995).Diffusion of Innovations: Modifications of aModel for Telecommunications. Springer Berlin Heidelberg, 25-38. .

Simiyu, C. N., \& Oloko, M. (2015). Mobile money transfer and the growth of small and medium sized enterprises in Kenya: a case of Kisumu city, Kenya. International Journal of Economics, Commerce and Management, 3(5), 1056-1065.

Söderberg, B. a. (2011). Mobile Money Payments among the Micro business enterprises in Uganda. 1(3), 273-288.

Sun. (2006). Causal Relationships Between Perceived Enjoyment and Perceived ease of Use: An Alternative Approach. Journal of The Association for Information Systems.

Talom, F. S. G., \& Tengeh, R. K. (2020). The Impact of Mobile Money on the Financial Performance of the MSMEs in Douala, Cameroon. Sustainability, 12(1), 183.

Talom, F. S. G., \& Tengeh, R. K. (2020). The Impact of Mobile Money on the Financial Performance of the MSMEs in Douala, Cameroon. Sustainability, 12(1), 183.

Tat. (2018). the opportunities and challenges of the mobile payment services in Sweden $267890 / / 2018$.

Tobbin, P., \& Kuwornu, J. K. (2011). Adoption of mobile money transfer technology: structural equation modeling approach. European Journal of Business and Management, 3(7), 5977.

Tumaini, I. N. (2016). The Impact of mobile money services on the growth of micro, small and medium enterprises in Nkasi district council (Doctoral dissertation, Mzumbe University).

Wadada. (2015). The significance of the Mobile Money Transfer facilities on the business performance of the mobile money agents in Kukuubo business area in Uganda.

Wambari. (2009). Mobile Banking In Developing Countries-A Case Study on Kenya. Information Technology, University of Applied Sciences. 